\title{
ON THE SECULAR MOTION OF A FREE MAGNETIC NEEDLE. II. ${ }^{1}$
}

By L. A. Bauer.

$\mathrm{A}$ CCORDING to the principle explained in the first part of this article, all the curves on the two plates given have been constructed. In this paper no attempt at a detailed account of material employed, or of construction formula, can be given. It will suffice to present in tabular form the final construction data.

With the aid of Tables I. and II. appended, the curves on Plate I. were drawn. Only a part of the material collected by the writer has been utilized thus far. The object was to give only so much as was absolutely necessary to establish the conclusions here given. To be able to do this to the best advantage, it was the aim to select such stations as would exhibit most clearly the various phases of the secular variation. To further facilitate the study, most of the stations were selected approximately in latitude $40^{\circ} \mathrm{N}$., and encircling the earth. The idea was to make a first attempt with the aid of such stations to follow a secular wave around the globe. It will be seen by turning to the plate, that the points (the intersections of the broken lines) which represent the mean values $\left(D_{0}\right.$ and $\left.I_{0}\right)$ for each station have been placed in the latitude of that station. Owing to the difference in the size of the curves, the real difference in longitude between the various stations could not be preserved; the points $\left(D_{0}, I_{0}\right)$ have, however, always been placed relative to each other in the proper longitude. This plate does not exhibit everything as clearly as the author would have wished; a larger scale could have been employed to good advantage. It should be remembered, however, that these curves have been drawn for the first time, and that in the nature

${ }^{1}$ A paper read before the National Academy of Sciences, Washington, April 16, 1895; concluded from page 465 . 
of the case this preliminary chart had to be more or less a trial one. The author hopes to be able to present, in the near future, a more complete and more comprehensive picture of the secular variation of geomagnetism.

But one more point with regard to the construction of the curves remains to be referred to. By turning to the Paris curve, it will be seen that the curve has been drawn from 1540 to 1890 . For this station we possess declinations $154 \mathrm{I}-1895$, but inclinations only from $167 \mathrm{I}$ to 1895 . How was it possible then to construct the curve from 1540 to $167 \mathrm{I}$, since for this interval we possess the knowledge of but one ordinate, viz., declination? In this way. From the declination interpolation formula, it is found that the minimum value, $-9^{\circ} .6$, or maximum easterly digression, was reached in about 1580 . The secular variation curve must then have run in 1580 tangent to the declination ordinate corresponding to the value of $9^{\circ} .6 \mathrm{E}$. With the aid of this fact the curve can be extended backward from $167 \mathrm{I}$ to 1580 . Having done this, we can scale off an approximate value of the inclination for 1580 , i.e. for a date for which we possess no such observations. This method of deriving inclinations for periods for which no data are at hand is here given for the first time. That the values thus derived can be relied upon to within $I^{\circ}$ to $3^{\circ}$, is shown from the following. The scaled value of the inclination for Paris in I 580 lies between $70^{\circ}$ and $72^{\circ}$; Norman observed at London in I $576,7 \mathrm{I}^{\circ} .8$. This would imply a value for Paris lying between $70^{\circ}$ and $71^{\circ}$. Hence the value $71^{\circ} .0 \pm 1^{\circ} .0$ cannot be far from the truth. With this value we can now extend the use of our interpolation formula, which had been established for the epoch $1671-$ I890. The formula gives for $1580,71^{\circ} .0$; we can consequently use it without great error back to 1580 . The drawing of the curve can thus be undertaken without difficulty. Between the years I $54 \mathrm{I}$ and $\mathrm{I} 580$ we know that the easterly declination was increasing; hence the secular variation curve, I54I-I580, must have approached the tangent point (1580) from the left. This part of the curve (154I-I580) is of course determined but very roughly, as no other values of the inclination were at hand than the extrapolated ones from the formula; but the direction of the motion 
has been determined, and that is the chief object of these investigations. It is seen that from I 54I to I890, i.e. for over 350 years, the curve proceeded clockwise. In precisely the same way, the London curve was extended from i 576 to I 540 ; the Rome curve from 1640 to 1508 . In the latter case the direction has therefore been determined for well-nigh 400 years. For the epoch of maximum easterly declination, viz., $1 \mathrm{I}^{\circ} .6 \mathrm{E}$. in about 1570 , we scale off an inclination of $62^{\circ} \pm 1^{\circ} .5$. As the earliest reliable inclination observed is that of Norman at London in $1576,7 \mathrm{I}^{\circ} .8 \pm \mathrm{I}^{\circ}$, the value scaled for Rome can boast of being one of the oldest that has come to our knowledge.

The first point to be observed is that for all the stations (24) on the chart, the motion proceeds throughout in the direction of the hands of a watch. This law has now been tested for more than one hundred observation series scattered over the earth. Where the data could be relied upon, or the series covered a sufficient time interval, the law was found to hold in every case. As the secular variation curves are not simple geometrical ones, but are broken up by a number of smaller waves, the writer does not mean to say that if the curves are drawn on a very large scale and, say, from month to month, the clockwise motion will obtain throughout all the very small loops of which the curve may be composed. It is simply asserted that in every case for the larger part of the curve, that is, for the secular variation broadly considered, the law holds for the interval for which the curves have been drawn. The law has been furthermore tested with the aid of the published magnetic charts, viz., the isogonic and the isoclinic charts for the epoch 1780-1885. From these charts the data were scaled for the intersections of the parallels of latitude $60^{\circ} \mathrm{N}$., $40^{\circ} \mathrm{N}$., $20^{\circ} \mathrm{N}$., $0^{\circ}$, $20^{\circ} \mathrm{S}$, $40^{\circ} \mathrm{S}$., $60^{\circ} \mathrm{S}$, with the meridians $20^{\circ}$ apart. The secular variation curves for parallels of latitude $40^{\circ} \mathrm{N}$., $0^{\circ}$ and $40^{\circ}$ S., i.e. $3 \times 18=54$ curves, have been drawn. For about a dozen there was some doubt as to the direction of the curve; in the rest, the clockwise motion again revealed itself. The doubtful curves were at such points on the earth's surface where the data are very meager, or where for the interval drawn the curve is in reality very small or nearly a straight line, i.e. the greater part of the 
variation occurs in the inclination, the declination suffering very little change (see, for example, Manila curve). We believe then that we can safely draw our first conclusion, -

In consequence of the secular variation of geomagnetism, the north end of a freely suspended magnetic needle viewed from the center of suspension of the needle, moves on the whole earth in the direction of the hands of a watch.

So much care has been given the establishment of this law for two reasons :-

a. Because, knowing now that it is a law that the secular variation observes, the means are given herewith to judge somewhat as to the value of doubtful data. ${ }^{1}$

b. Because it is recognized that in the above law we have already one criterion, with which to decide between some of the causes of the secular variation that have been suggested. This law will doubtless play an important rôle in the next step of these investigations, - the mathematical examination and critical discussion of the possible causes. ${ }^{2}$

Very little can as yet be said as to the true geometric nature

1 This can be elucidated by the following example. In 1885 , Mr. Schott, the wellknown geomagnetician, drew the secular variation curve for a mean station of New England, and for the interval $1820-1885$. He knew approximately when the needle had reached its maximum easterly point, and also the value of the declination for this period. $\mathrm{He}$ could determine then the line to which the curve would have to run tangent, prior to 1820. Although he had had an experience of over forty years in terrestrial magnetic matters in the United States, he nevertheless did not dare to extend the curve back to this tangent line for the reason that he could not tell whether the extension would have its - convex side turned downwards or upwards. Inclinations had been observed at Boston in 1780 , but as they appeared doubtful to him no use was made of them. When the writer laid his preliminary investigations before the A. A. A.S. in 1892 , he could then say how Mr. Schott's curve ought to be extended prior to 1820 , viz., the convex side must be turned downwards in order to make the direction of the motion correspond to that obtaining at the European stations. Or, if the observed inclinations for 1780 were utilized, the curve would proceed in the direction as prescribed by the law. The curve for Boston was then exhibited for the period $1780-1885$, and the direction prior to 1780 also indicated with the aid of the observed declinations. In the latter part of 1894 , the writer's attention was called by Professor Cleveland Abbe to a work in which he obtained an observed inclination at Boston for the year $\mathbf{1 7 2 2}$, this being probably the earliest observed inclination in the United States. With these data the Boston curve has now been laid down from 1722 to 1885 . It is seen that the law of the motion obtains throughout, and that consequently the observed inclinations for 1780 cannot be far from the truth.

${ }^{2}$ See American Journal of Science for August, 1 895, and following numbers. 
of the secular curve. To the great question, however, whether it consists of a single branch or of several, an answer can be attempted. It may be remarked that it would be far more astonishing if the curve were a single closed one, than if it were shown to consist of branches or loops, since the daily and annual variation curves are known to be very complex indeed. Indications of loops are shown at two stations, Rome and the Azores. At the first station, by means of the so-called compass-charts of the 14 th and I 5 th centuries, we are able to gain some knowledge of the magnetic bearing of the needle for that epoch. On these charts the directions from port to port are laid down magnetically. By comparison with charts on which astronomical directions are given, some knowledge of the magnetic declination for the period of the compass-charts can be obtained. Thus it was found that according to the compass-charts of 1436 , by Andrea Bianco, the magnetic declination at Rome ought to be about $5^{\circ} \mathrm{E}$. If we now assume that the law governing the secular variation of the declination from 1508 to 1890 holds good also from 1400 to 1508 , we find that in 1400 the declination ought to be $12^{\circ} \mathrm{W}$., and for 1436 , $7^{\circ} \mathrm{W}$. Prior to 1400 the westerly declination would be increasing. The material with which Bianco's charts were constructed is doubtless older than 1436 . If we make the most favorable assumption, however, that the value $5^{\circ} \mathrm{E}$. refers to 1436 , we find a difference of $12^{\circ}$ between compass-charts and formula. For 1400 the difference would be even $17^{\circ}$, and prior to that still greater. The best plausible explanation we can give of such large discrepancies, is that a different law of the secular variation came into play, or, in other words, a loop was described prior to I 500 . A similar conclusion is reached at the Azores station, by considering the observed compass-bearing of Columbus in 1492, in the vicinity of these islands. Even if we assume that the value is erroneous so far as $6^{\circ}$, there still remains an outstanding difference between observation and formula of $8^{\circ}$. The writer does not mean to say that the foregoing considerations should be regarded as sufficient proofs, but simply as indications of loops. The singular points exhibited at some of the stations drawn, e.g. Acapulco and station, $40^{\circ} \mathrm{N}$., $40^{\circ} \mathrm{W}$., are doubtless due chiefly to inaccurate data. If 
we compare the two curves $40^{\circ} \mathrm{N}$., $60^{\circ} \mathrm{W}$., and $40^{\circ} \mathrm{N}$., $40^{\circ} \mathrm{W}$., we find that they both observe the law of motion, and yet there is a striking difference between them. The former follows the United States type, the latter the European. Some remarkable change in the curve must have occurred between these two stations. The European type cannot change suddenly into that of the United States. The change must be a progressive one, and be made by means of loops or singular points. It is probable that the curves in this region will contain such singularities.

As to the period, nothing definite can be said as yet, and it moreover appears questionable whether there really exists a secular variation period, at the close of which the needle describes the same orbit it did before. The time interval between the epochs of maximum westerly and easterly digression of the needle can be determined for a number of stations to within about ten per cent. Thus this interval for London is, $1812-1580=232 \pm 10$ years; for Paris, $1809-1580=229 \pm 10$; for Rome, $1810-1570=240 \pm 15$. Accordingly, we might say that this interval for western Europe is about 235 years. For the eastern part of the United States the interval appears to be on an average about 150 years. We have a proof here at once that if the secular variation period has the same length all over the earth, we cannot then regard the interval between the extreme digressions as covering half the period; for, if this were so, then the period for Europe would be about 470 years, that for the eastern United States only about 300. We are then forced to conclude that either the period is different for various portions of the earth, or that the secular curve is not a single closed curve, but consists of loops. This is our second conclusion.

Now let us follow a secular wave around the earth. We will begin with London, and proceed in an easterly direction. The London curve seems to be approaching the upper extreme point, i.e. the inclination is diminishing with a speed that has become less and less ever since about 1810 , or, in other words, it is nearing a minimum value which may be reached about the middle of the next century. Paris appears somewhat nearer this phase; Rome and Berlin still nearer, where it will probably take place shortly. At Tiflis this phase has already been passed, in about 1875. At 
[Vol. III.

Bombay the minimum inclination phase has long ago occurred, and in about $\mathrm{I} 880$ the curve had already reached its maximum easterly digression. Irkutsk, Peking, Manila, Petropawlowsk, station $40^{\circ} \mathrm{N}$., $180^{\circ}$ E., are either nearing the maximum inclination phase or have already passed through it. It is extremely difficult to say through what phase the San Francisco curve has passed, for the reason that in the Pacific Ocean and on the western coast of the United States, secular waves of opposite phase, but of different amplitudes, seem to make their appearance, and consequently partially annihilate each other. St. Louis, Boston, Bermudas, $40^{\circ} \mathrm{N}$., $60^{\circ} \mathrm{W}$., have passed through their extreme lower points, and are approaching now the maximum westerly digression. The latter will take place in time in the reversed order of the stations. At station $40^{\circ} \mathrm{N}$., $40^{\circ} \mathrm{W}$., the -maximum westerly elongation has just occurred, or will occur soon. At the Azores it took place about 1852 , and the needle, as at London, is bent now upon reaching its upper extreme position. We have now followed a wave around the earth.

Our next conclusion is that the secular variation curves appear to develop themselves more and more as we go around the earth eastwardly; or, in other words, the secular wave appears to travel in the main, roughly speaking, westward. We might then conclude that by obtaining a composite of the various parts of the successive secular variation curves for stations, somewhere near a parallel of latitude, we could get the total curve. If we do this mentally, we shall find at once that the curve constructed thus is not a single looped one, as there are two regions where the needle is passing through a maximum inclination phase, and likewise two where the maximum easterly (or minimum westerly) phase is taking place.

But what does this unfolding of the secular variation curve, with eastward progression, imply? If this continuous development has been caused by a wave traveling from east to west around the earth, would it not follow that if we made an instantaneous circuit of the earth in an easterly direction with a free magnetic needle, the same phenomenon would unfold itself from station to station, as occurs at any fixed station in the lapse of time? Let us see if 
this be true. In 1885 we will start from a point, the latitude of which is $40^{\circ} \mathrm{N}$, and longitude $0^{\circ}$. We will take with us a free magnetic needle, and travel with it eastwardly around the earth along the parallel; $40^{\circ} \mathrm{N}$. At points distant $20^{\circ}$ in longitude, we will observe the direction of the needle; measuring the declination and the inclination. Throughout the circuit the needle is constantly changing its direction. If we now suppose that the center of suspension of the needle is fixed, but the needle itself subject to the changes encountered during the circuit, we can construct the curve described by the north end, in a manner analogous to that which was followed in drawing the secular variation curves. We thus obtain the striking curve exhibited on Plate II., - the heavy curve on the left. The only difference from the secular variation curves is, that instead of time we now have longitude marking the various points of the curve. Instead of actually making the circuit, we can obtain the necessary data from the excellent isogonic and isoclinic charts for I885, constructed by Professor Neumayer, director of the German Naval Observatory. The broken places correspond to the data for the points $20^{\circ}$ distant in longitude, and lying in latitude $40^{\circ} \mathrm{N}$. It will be observed that this curve also proceeds throughout in the direction of the hands of a watch; even the small loop follows this law. Furthermore, the part without the loop exhibits a great similarity to the secular variation curves for London, Paris, and Rome. Is this mere accident? Suppose we make our circuit along other latitudes, or for other epochs, - will a similar condition of things obtain? To answer this the writer has drawn first the instantaneous curves for latitudes $75^{\circ} \mathrm{N}$, $70^{\circ} \mathrm{N}$, $60^{\circ} \mathrm{N}$., $50^{\circ} \mathrm{N}$., $40^{\circ} \mathrm{N}$., $20^{\circ} \mathrm{N}$, $0^{\circ}, 20^{\circ} \mathrm{S}$, $40^{\circ} \mathrm{S}$, $60^{\circ} \mathrm{S}$., from data of 1885 , and secondly the curves for $40^{\circ} \mathrm{N}$, $0^{\circ}$, and $40^{\circ} \mathrm{S}$., for the additional years $\mathrm{I} 780$ and 1829 . In every case the direction of motion was clockwise. On Plate II., these latter curves are drawn for the three years; the necessary data are given in Table III. It will be observed that although the nine curves present many irregularities and singularities, they nevertheless all unite to exhibit a hitherto unsuspected law. Before we formulate the new conclusion to be drawn, let us see what we shall get if we make the circuit in some other way than alorig a 
[VoL. III.

parallel of latitude. Of course the circuit must always be made eastwardly as the waves come, generally speaking, from the east. Likewise is it apparent that for every circuit we shall get a closed curve. At first sight it might appear more natural to make the circuit along a magnetic parallel. If we define the latter as an isoclinic, then the curve will reduce to a straight line, since along an isoclinic the inclination is constant, the declination alone varying. If we regard an equipotential line as a magnetic parallel, and make the circuit e.g. along the zero equipotential line or along the magnetic equator, we get the peculiar curve given on Plate II., middle figure. This curve has a large loop proceeding clockwise, and two small loops, one going anti-clockwise and the other clockwise. It will at once be seen that this curve does not present such a striking similarity to the secular variation curve. It seems then that the circuit must be made somewhere near a parallel of latitude. Is this not an indication that the secular variation is in some manner connected with the rotation of our mighty geomagnet? This matter is at present being investigated. Our next conclusion is then :-

The north end of a free magnetic needle, viewed from the center of suspension of the needle, moves clockwise in making an instantaneous easterly circuit of the earth along a parallel of latitude; or,

The north end of a free magnetic needle, whose center of suspension is fixed in sjace close to the earth's surface, will describe a curve as the earth rotates under it, which as viewed from the center of suspension of the needle, moves anti-clockwise. ${ }^{1}$

In the foregoing we have already hinted at a connection between the secular variation and the distribution of geomagnetism, in that they both observe similar laws. This connection is also revealed in another way. By turning to Plate 1., it will be seen that the largest secular curves seem to occur at stations somewhere near the equator, - see Ascension and St. Helena islands. Likewise the curve for Rome is smaller than the one for Cape Town, lying in

\footnotetext{
1 The original formulation of this law was given in the first form. The curves are indicated then on Plate II., as proceeding clockwise. For the second form the arrows would have to be reversed. The motion is now reversed since the earth rotating from west to east is equivalent to making a westerly circuit of the earth with the needle.
} 
about the same latitude south. Turning now to Plate II., it will be seen that a precisely similar condition of things prevails. Thus the largest instantaneous curve is described at the equator; likewise the curves for $40^{\circ} \mathrm{S}$. are larger than those for $40^{\circ} \mathrm{N}$. A connection seems to prevail also with regard to the loop in the northern hemisphere. This cannot be exhibited here, however.

Our final conclusion is then:-

The secular variation and the prevailing distribution of geomagnetism appear to be closely related. 


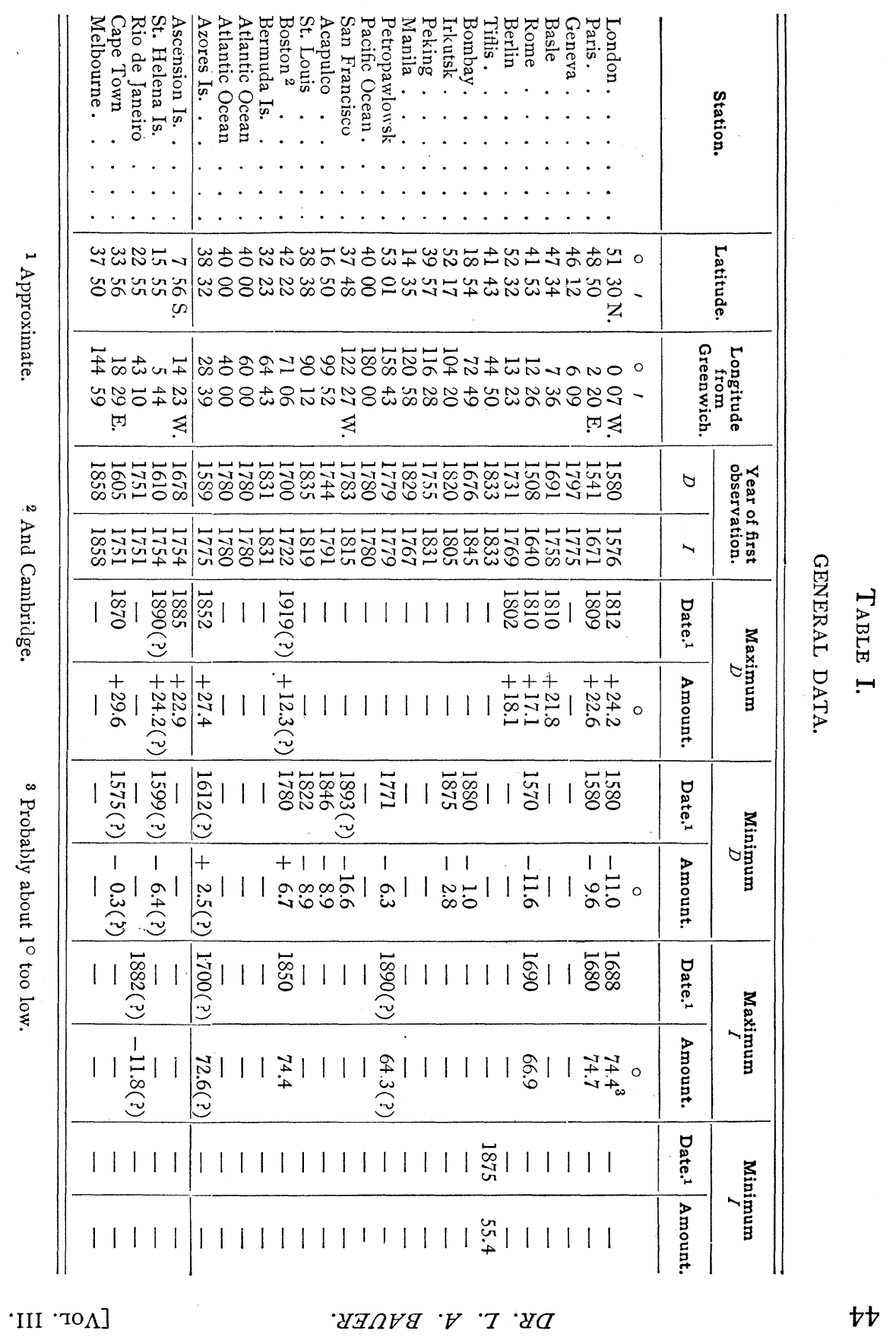


No. I.]

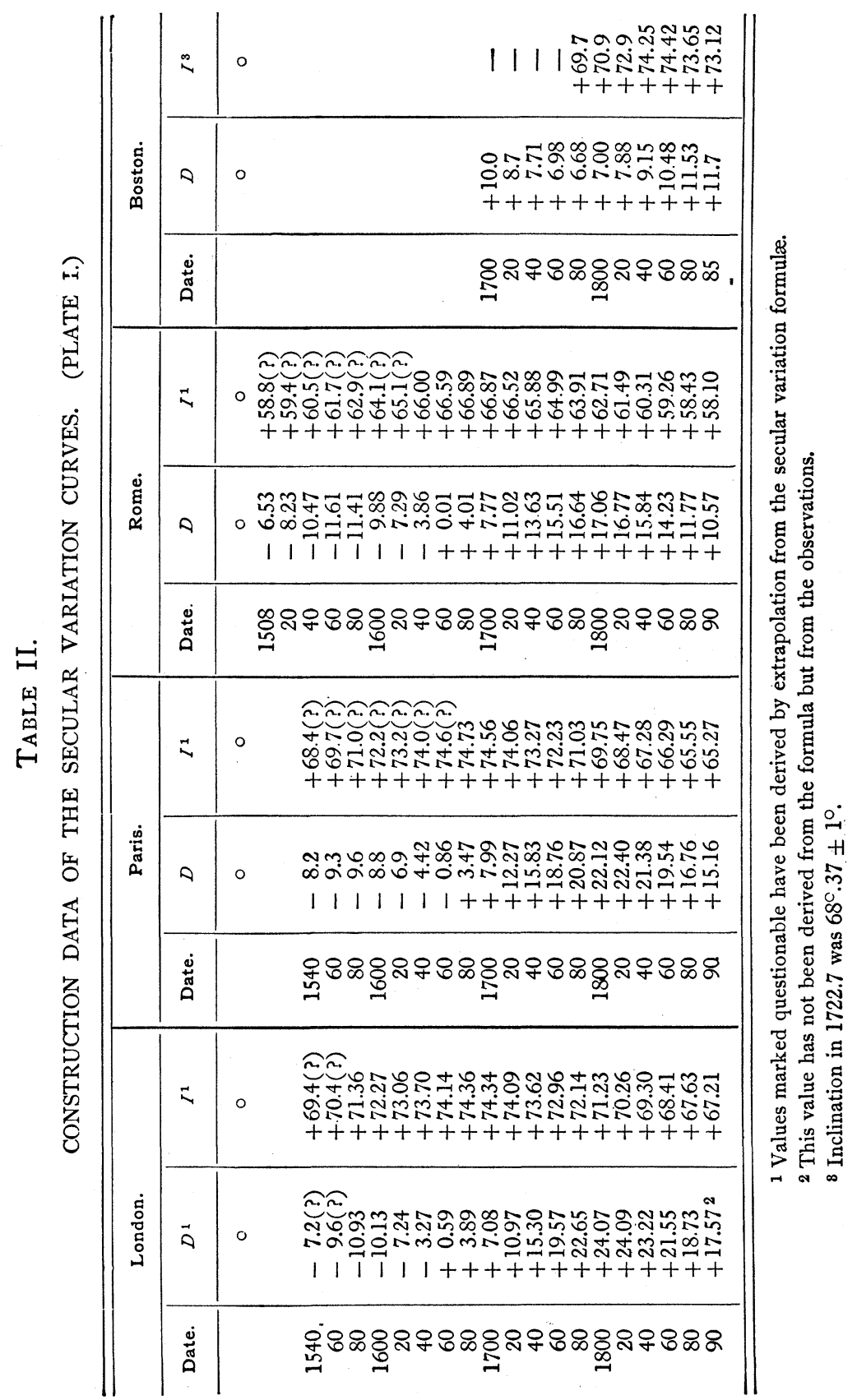




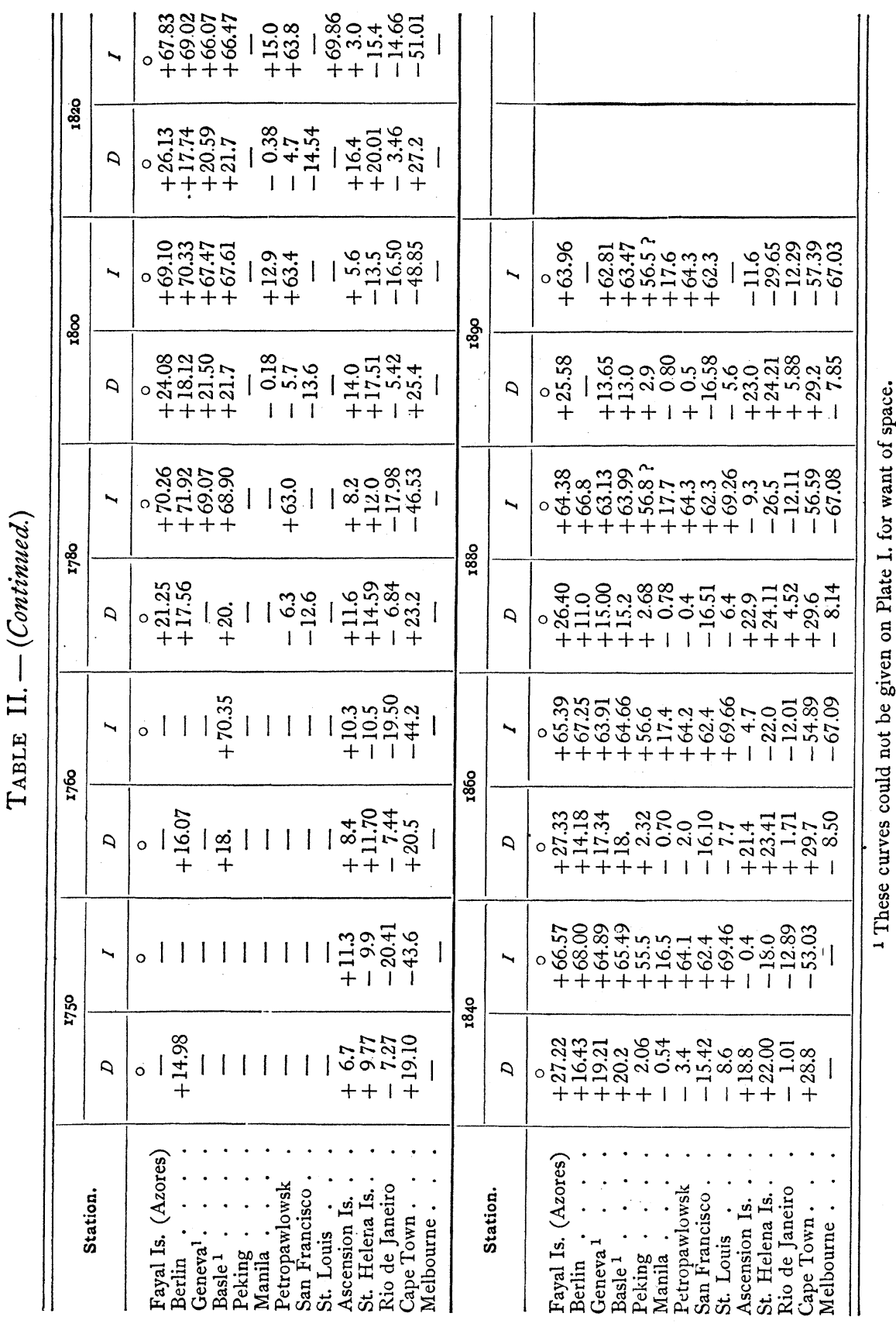


No. I.]

SECULAR MAGNETIC VARIATION.

\begin{tabular}{|c|c|c|c|c|c|}
\hline \multirow{3}{*}{ 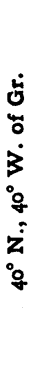 } & - & 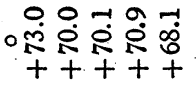 & \multirow{3}{*}{ 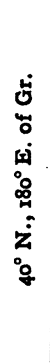 } & 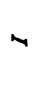 & 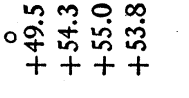 \\
\hline & 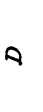 & 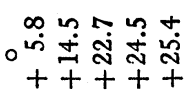 & & $\theta$ & ○芯芯 \\
\hline & هُ & 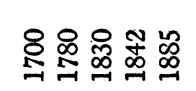 & & 迆 & 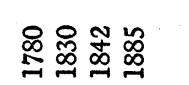 \\
\hline \multirow{3}{*}{ 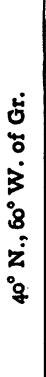 } & - & 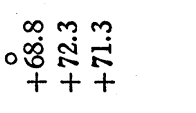 & \multirow{3}{*}{ 恶 } & 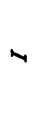 & 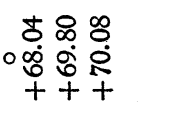 \\
\hline & $\triangle$ & 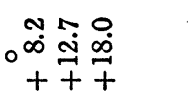 & & $\triangle$ & 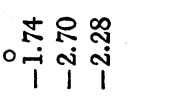 \\
\hline & لّ & 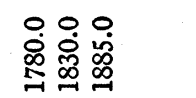 & & ڤัٌ & 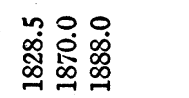 \\
\hline \multirow{3}{*}{ 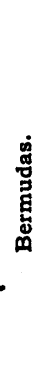 } & $\checkmark$ & 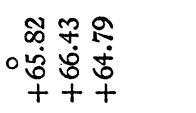 & \multirow{3}{*}{ 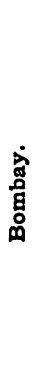 } & - & 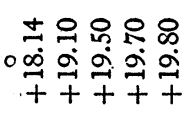 \\
\hline & 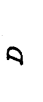 & 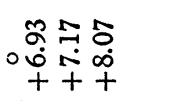 & & $Q$ & 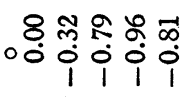 \\
\hline & 䞤 & 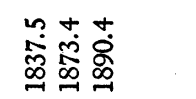 & & मूँ & 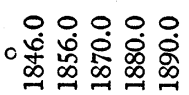 \\
\hline \multirow{3}{*}{ 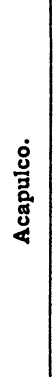 } & $\checkmark$ & 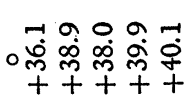 & \multirow{3}{*}{$\stackrel{\dot{m}}{\stackrel{\dot{m}}{*}}$} & - & 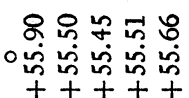 \\
\hline & $\theta$ & î̀ & & $\triangle$ & 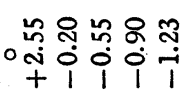 \\
\hline & هั & 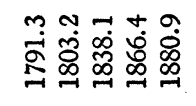 & & ڤัँ & 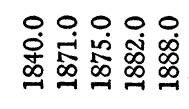 \\
\hline
\end{tabular}



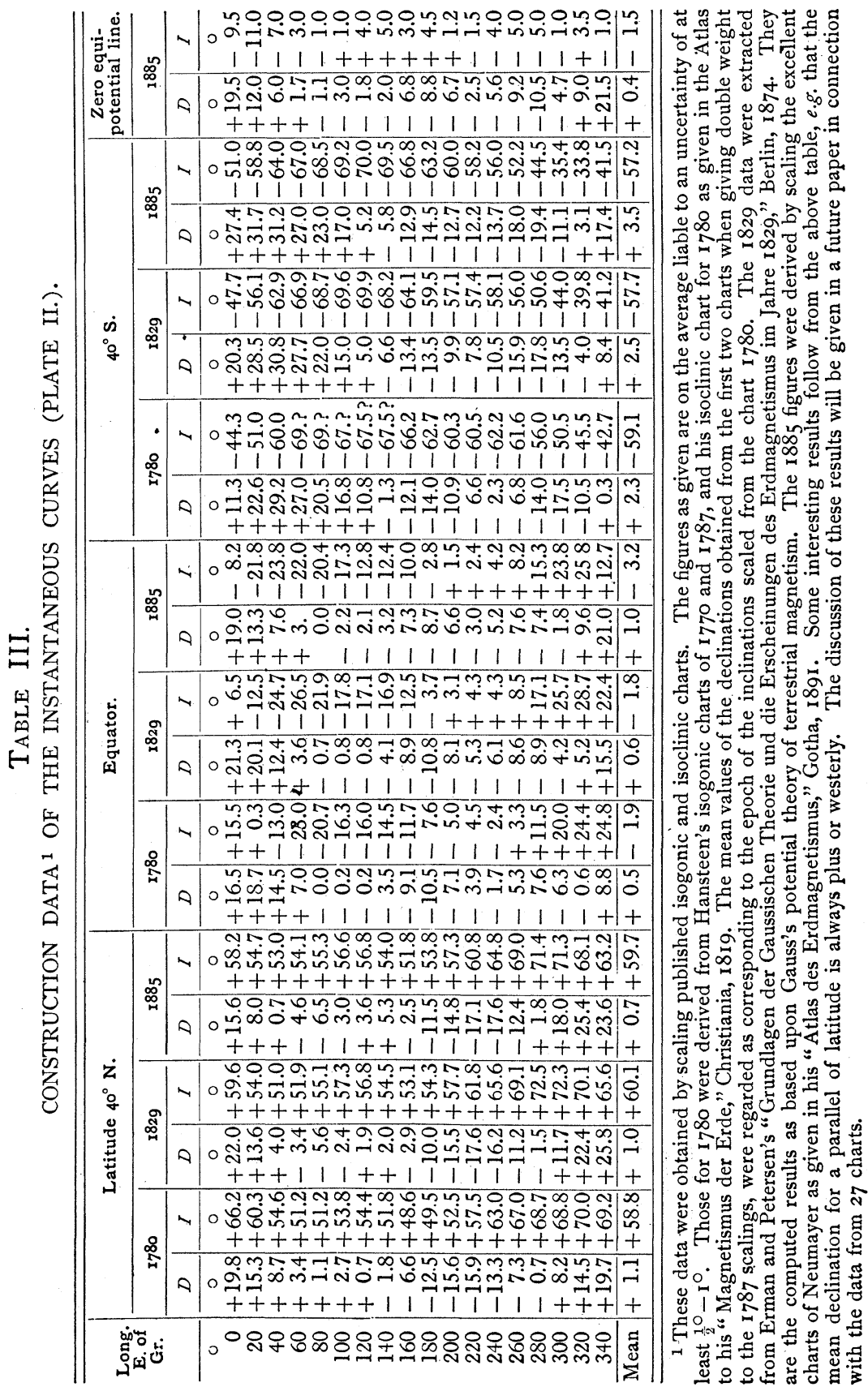


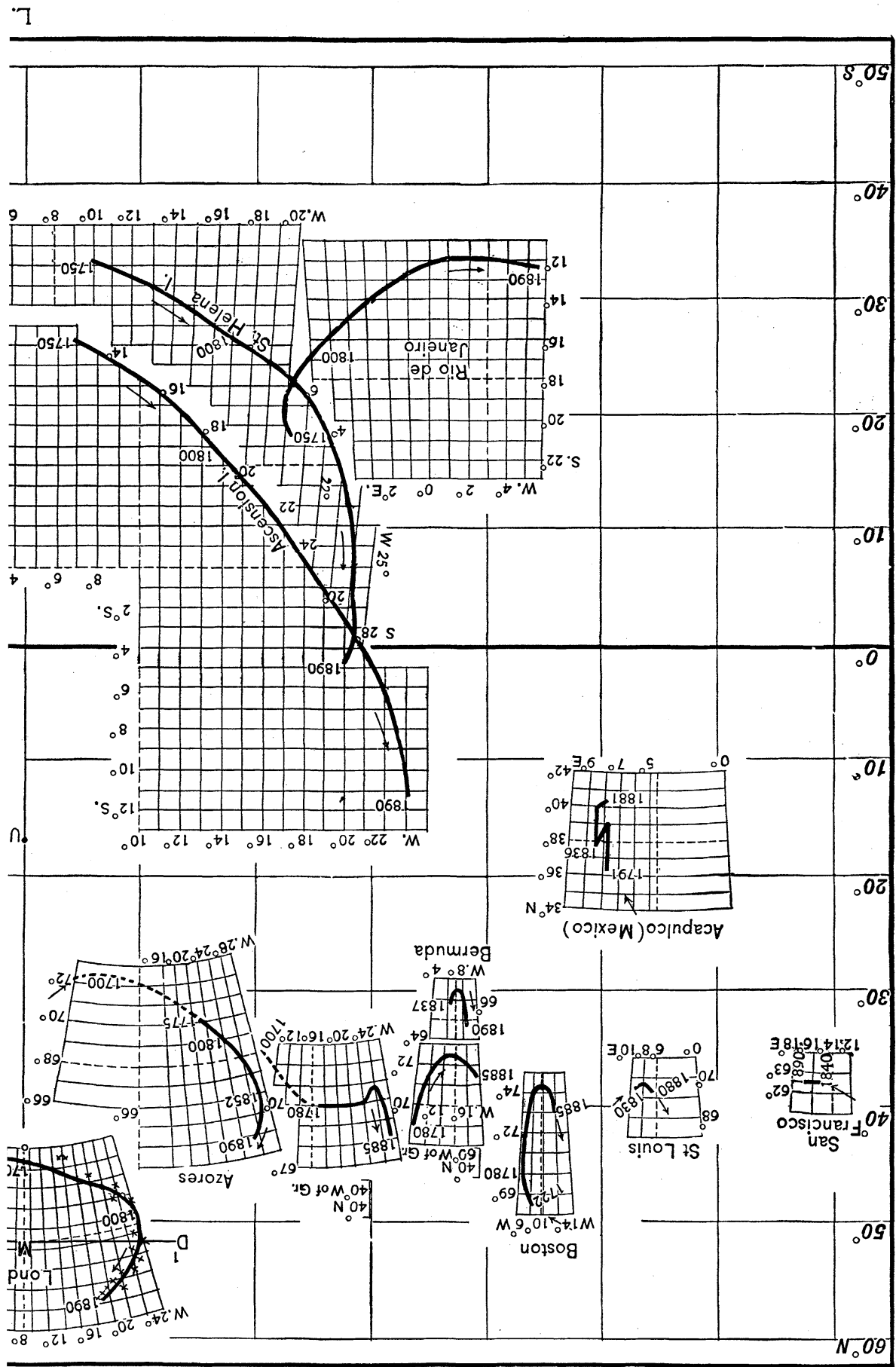

$8^{t}$ ว.8हd วכหנ OL 


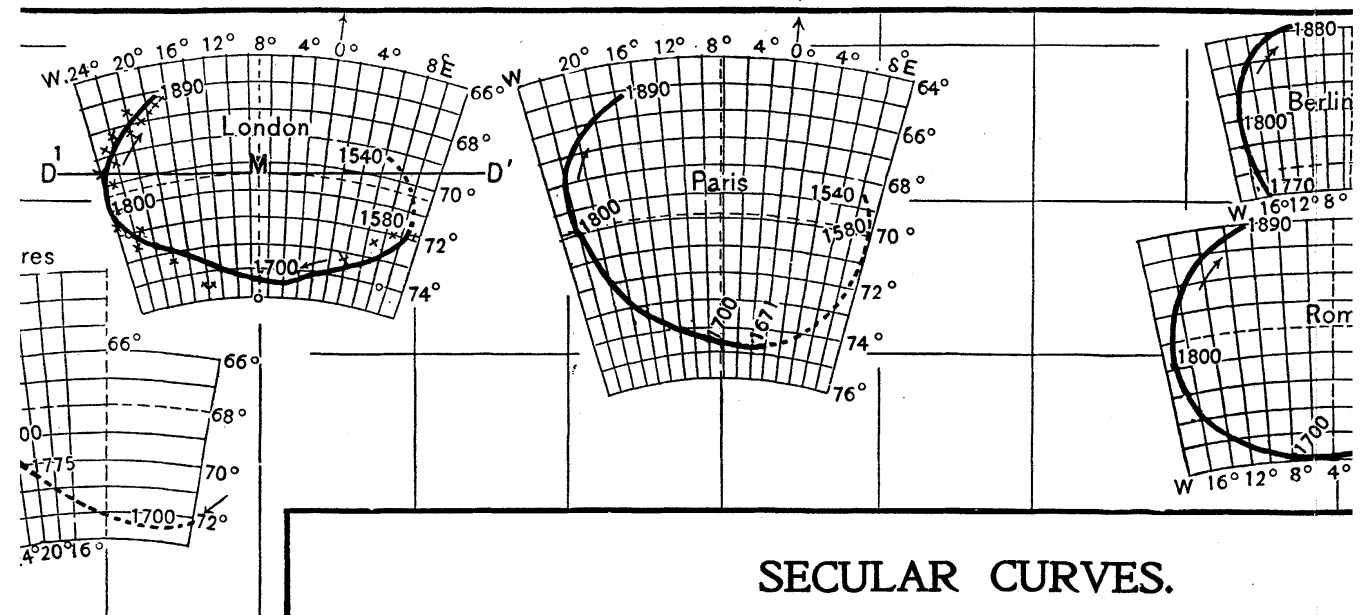

[In consequence of the secular variation of terrestrial magnetism, the nortl suspended magnetic needle describes some kind of a curve. The curves giv represent the central projections of these secular variation curves. They were ing the half-length of the needle to be $20 \mathrm{~cm}$. (7.88 inches), and as they wou observer standing at the point of suspension of the needle and looking tor end. The original scale has been reduced so that the curves now corresponc of needle, $15.5 \mathrm{~cm}$. or 6.1 inches.]

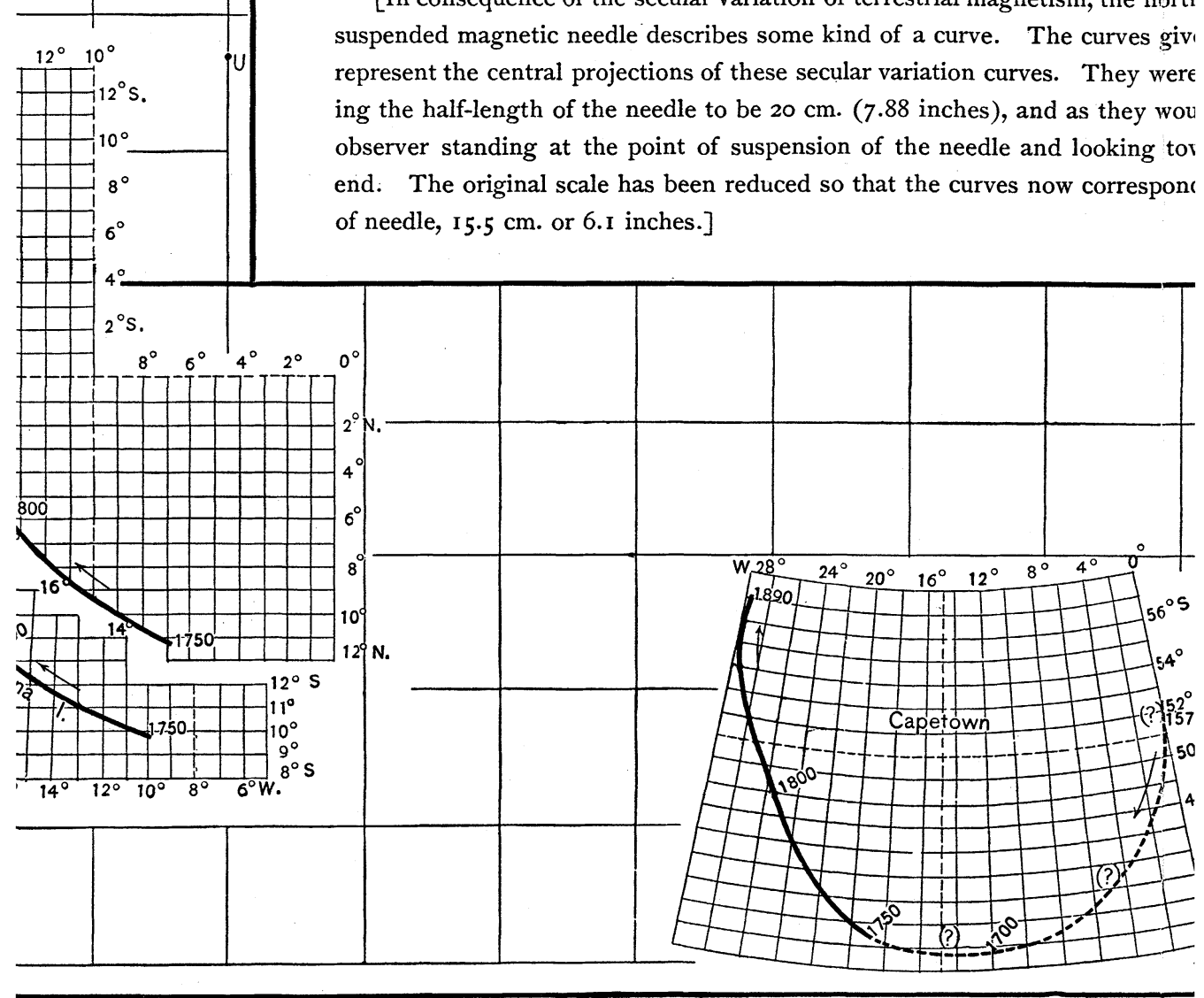

L. A. BAUER: SECULAR MAGNETIC VARIATION. I. 
BAUER. PLATE I.

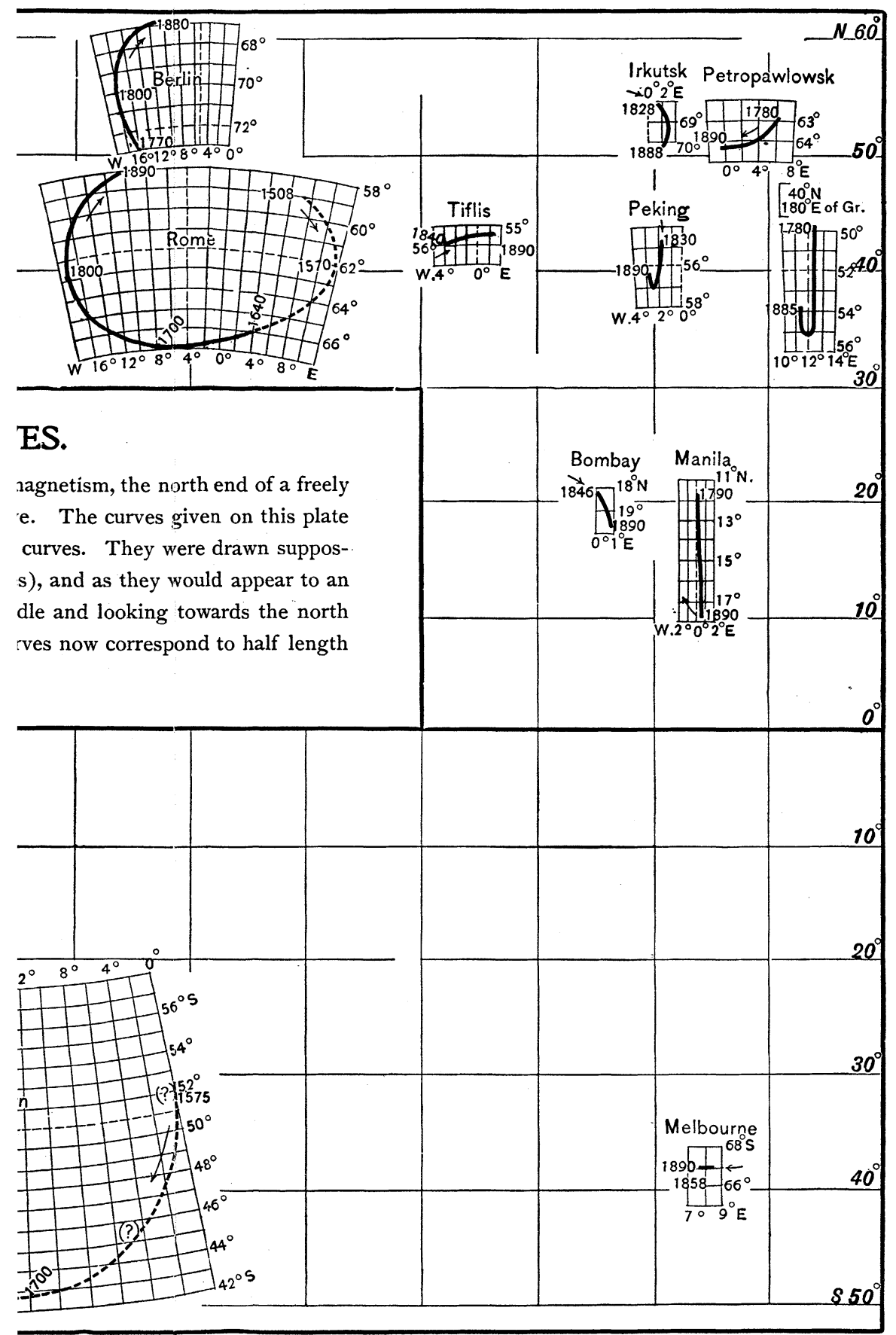

I. 
To face page 48 .

\section{INSTANTANEOUS}

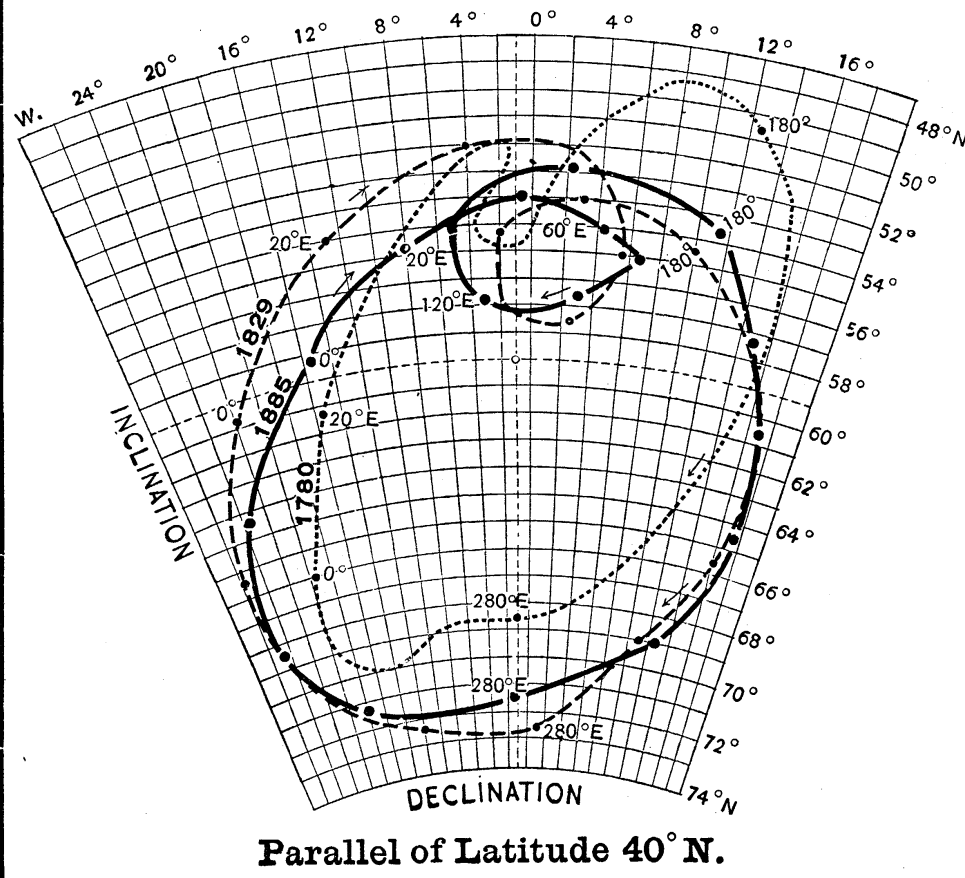

[In consequence of the earth's rotation, the north end of a free magnetic needle whose center of suspension is fixed in space close to the earth's surface describes some kind of a curve. The curves given on this plate represent the central projections of these curves. They are drawn supposing the half-length of the needle to be $20 \mathrm{~cm}$. (7.88 inches); and as they would appear to an observer standing at the point of suspension of the needle and looking towards the north end.]

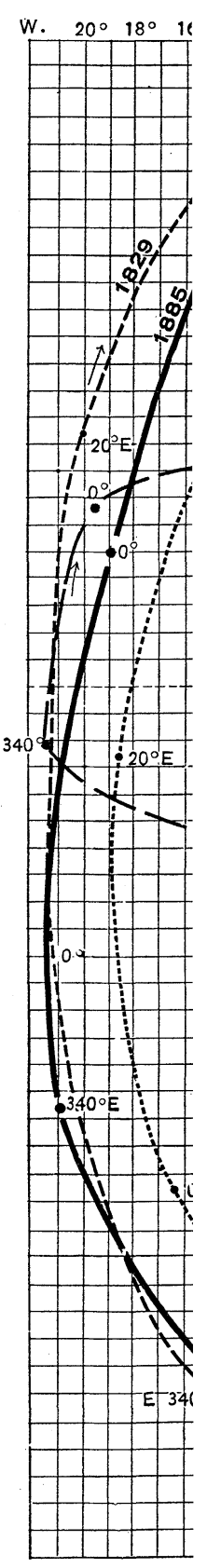




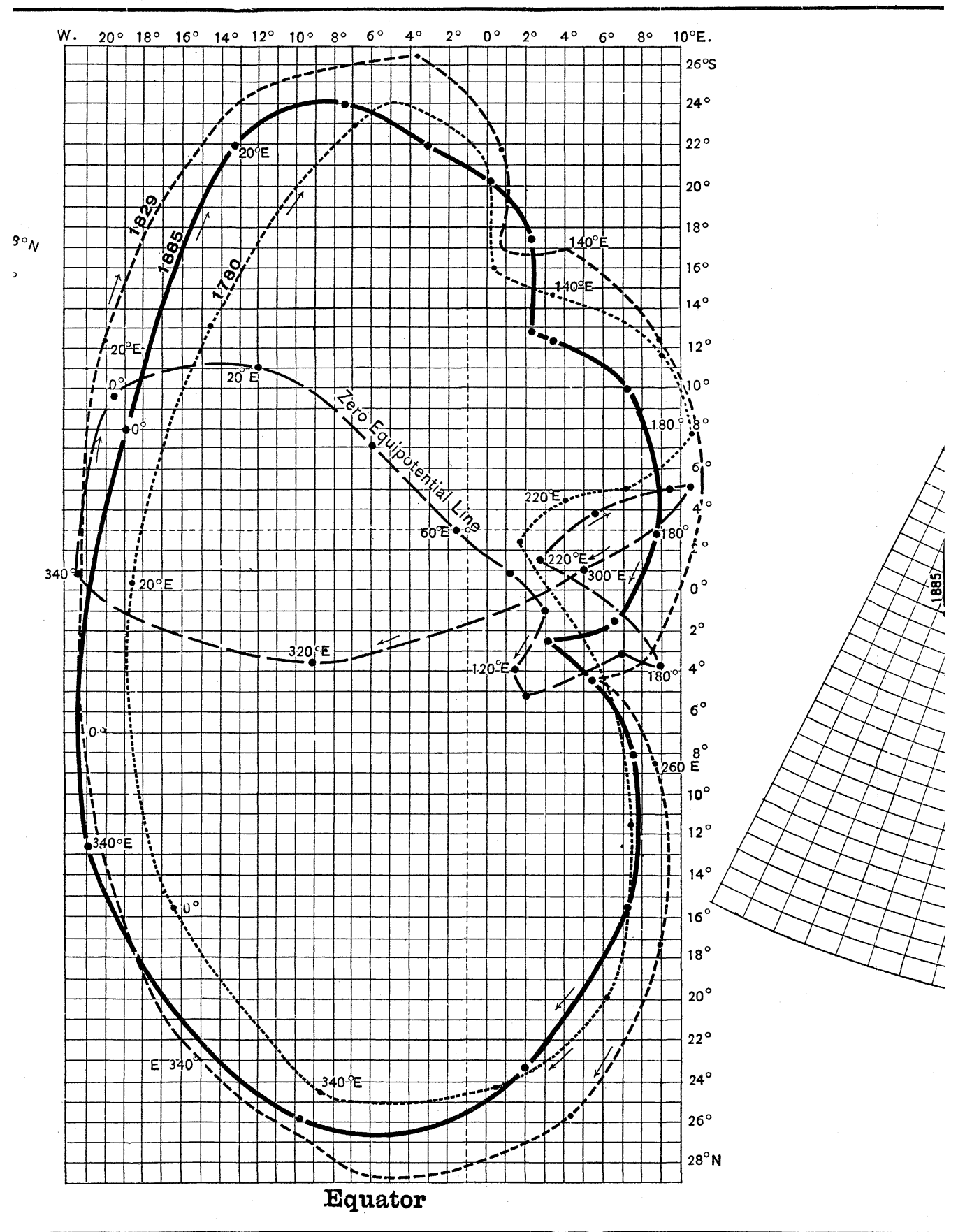

L. A. BAUER: SECULAR MAGNETIC VARIATION. II. 
BAUER. PLATE II.
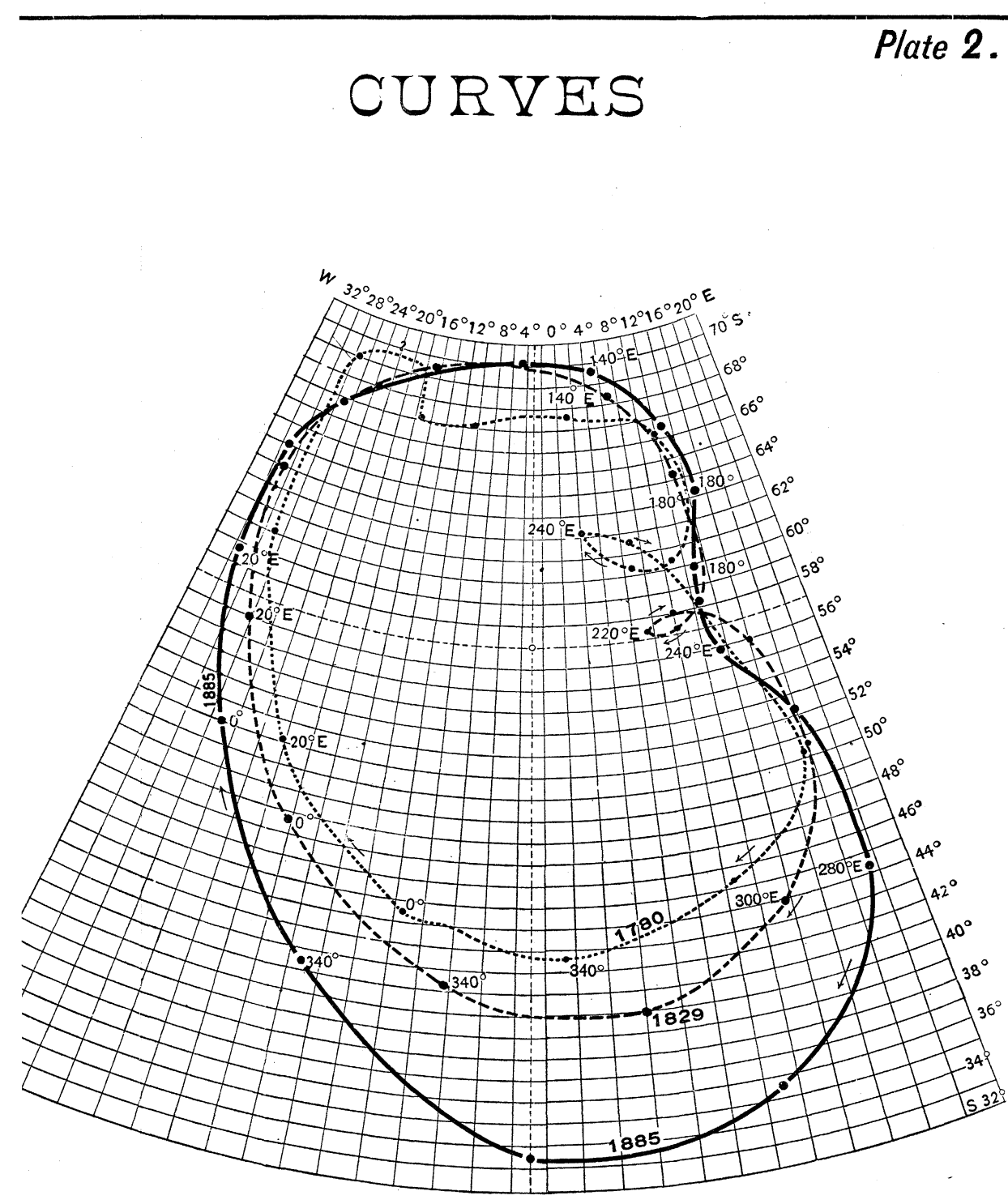

Parallel of Latitude $40^{\circ} \mathrm{S}$.

II. 